\title{
In-situ microbial colonization and its potential contribution on biofilm formation in subsurface sediments
}

\author{
Ji-Hoon Lee ${ }^{1}$ (D) $\cdot$ Bong-Joo Lee ${ }^{2} \cdot$ Uk Yun $^{2} \cdot$ Dong-Chan Koh' ${ }^{2}$ Soo Jin Kim ${ }^{1}$ \\ - Dukki $\mathrm{Han}^{3}$ - Tatsuya Unno
}

Received: 4 December 2018 / Accepted: 8 January 2019 / Published Online: 31 March 2019

(C) The Korean Society for Applied Biological Chemistry 2019

\begin{abstract}
Biofilms facilitate communication among microorganisms for nutrients and protect them from predators and harmful chemicals such as antibiotics and detergents. Biofilms can also act as cores for the development of clogs in many agricultural irrigation systems and in porous media. In this study, we deployed glass units at a depth of $20 \mathrm{~m}$ below the ground surface in the groundwater-surface water mixing zone, and retrieved them after 4 months to investigate the potential colonization of indigenous microbial community and possible mineral-microbe assemblages. We observed the periodic formation of microbial colonies by fluorescence dye staining and microscopy, and analyzed the composition of the microbial community in both the mineralmicrobe aggregates and groundwater, by next generation sequencing of the 16S rRNA gene amplicons using MiSeq platform. During the course of incubation, we observed an increase in both the mineral-microbe aggregates and content of extracellular polymeric substances. Interestingly, the microbial community from the aggregates featured a high abundance of iron redox-related microorganisms such as Geobacter sp., Comamonadaceae sp., and Burkholderiales incertae sedis. Therefore, these microorganisms can potentially produce iron-minerals within the sediment-microbeassociated aggregates, and induce biofilm formation within the
\end{abstract}

Ji-Hoon Lee $(\triangle)$

E-mail: jhlee2@jbnu.ac.kr

${ }^{1}$ Department of Bioenvironmental Chemistry, Chonbuk National University, Jeonju 54896, Republic of Korea

${ }^{2}$ Groundwater Department, Korea Institute of Geoscience and Mineral Resources, Daejeon 34132, Republic of Korea

${ }^{3}$ Faculty of Biotechnology, Jeju National University, Jeju 63243, Republic of Korea

This is an Open Access article distributed under the terms of the Creative Commons Attribution Non-Commercial License (http://creativecommons. org/licenses/by-nc/3.0/) which permits unrestricted non-commercial use, distribution, and reproduction in any medium, provided the original work is properly cited. groundwater borehole and porous media.

Keywords Bioclogging - Groundwater - Microbial community Subsurface biogeochemistry

\section{Introduction}

Biofilms play an important role in the formation of bio-clogging in various irrigation systems $[1,2]$ and in porous media $[3,4]$. Biofilms formed due to biomass accumulation and microbially induced precipitation of minerals in saturated subsurface environments can give rise to bio-clogging in the porous media $[1,5]$, and result in a decrease in the permeability of the subsurface environment. During growth, microorganisms excrete extracellular polymeric substances (EPS), which increase the cohesiveness of the cells and/or biomass, leading to the formation of biofilms $[1,6]$. EPS have slimy and gel-like characteristics, and their main constituents are polysaccharides, proteins, and nucleic acids. Thus, EPS can potentially accumulate biomass and inorganic substances, such as minerals and sediments and form biofilms.

Biofilms have been in focus for their application as bio-barriers to prevent the spread of pollutants and degrade them within the containments in the subsurface and groundwater $[3,7,8]$. However, biofilms have also resulted in the decreased efficiency in engineered bioremediation of contaminated groundwater [9]. Nie et al. [10] have reported on the changes in the microbial community of the soil supplemented with nutrients from septic tank effluent lead to the biofilm formation, using denaturing gradient gel electrophoresis analysis. However, the microbial communities contributing to the formation of biofilms in porous media and/or groundwater have not been well characterized.

In the present study, we investigated the microbial community that colonized on the in-situ-formed mineral-microbe aggregates, in the groundwater borehole. The study area or borehole was in a 
hyporheic zone, where groundwater and surface water mixing occurred. Therefore, we investigated the effect of dissolved oxygen (DO) and dissolved organic carbons (DOCs), potentially migrating along with the surface water into the groundwater, on microbial colonization and potential for biofilm formation in the porous media. This study could provide insight into the microbial community composition contributing to the formation of biofilms and/or mineral-microbe aggregates in subsurface-saturated porous media environments.

\section{Materials and Methods}

\section{In-situ incubation and colonization in groundwater}

Microscopic cover glasses (Marienfeld GmbH \& Co.KG, LaudaKönigshofen, Germany) were deployed into the groundwater borehole to examine possible microbial colonization on them. The groundwater borehole was described in the previous publication [11], and it was located within the mixing zone between stream water and groundwater in a heavy groundwater extraction area for agricultural use. Each cover glass was inserted into a plastic container (cell) with meshes on both sides of the container for water flow-through and 20-mesh cells were stacked up on a cylinder-type holder (Fig. 1). The cylinder-type holder was deployed into the borehole WJ2 [11] at a depth of $20 \mathrm{~m}$ below the ground surface, and retrieved for sampling the plastic cells containing the cover glasses at selected time points. Some of the groundwater and geochemical parameters were measured on-site and in the laboratory after being transported at $4{ }^{\circ} \mathrm{C}$, as indicated in Table 1.

Sampling of the colonized slides and confocal laser scanning microscopy (CLSM) analysis

The retrieved cover glasses were directly examined for potential microbial colonization on the glasses using the CLSM (TCS SP5/
AOBS/tandem scanning system, Leica Microsystems GmbH, Wetzlar, Germany). The sampled cover glass surface was stained with SYTO9 (fluorescent green; Life Technologies, Carlsbad, CA, USA) and lectin PHA-L (Alexa Fluor 594 conjugate; Molecular Probes, Inc., Eugene, OR, USA) for bacterial cells (nucleic acids) and EPS, respectively. The EPS play a critical role in the formation of structured multicellular bacterial communities or biofilms [1]. Thus, CLSM examination was performed to observe the association of bacterial cells with EPS on the aggregates formed on the glass surfaces.

Genomic DNA extraction and microbial community analysis Surfaces of the retrieved cover glasses were swiped with sterile cotton and the groundwater was filtered using a $0.45-\mu \mathrm{m}$ poresize, 47-mm diameter cellulose acetate membrane filters (Advantec, Tokyo, Japan) to collect the bacterial cells for DNA extraction. Cottons and filters were used for DNA extraction using the PowerSoil DNA isolation kit (MoBio Laboratories, Carlsbad, CA, USA). Three DNA extracts were pooled into one for both the glass-colonized and planktonic microorganisms, and were then used for further downstream experiments. The V1-V3 region of the 16S rRNA gene was amplified from the genomic DNA using the 16S rDNA fusion primer set (27F, 5-GAG TTT GAT CMT GGC TCA G-3 and 518R, 5-WTT ACC GCG GCT GCT GG-3), followed by sequencing using a GS-FLX sequencing system (Roche, Basel, Switzerland) by Macrogen (Seoul, South Korea).

The sequence was processed using Mothur ver. 1.33.3 [12], by referring the suggested standard operating procedure for 454 pyrosequencing [13-15]. Sequence errors were reduced by using a series of subroutine processes in Mothur, and were screened for chimeras using UCHIME [16]. After the removal of low-quality reads and non-bacterial sequences, the total number of sequences from the two samples was 13,361 . Total sequence counts were 5,921 and 7,440 for the glass surface (WJ2-S) and groundwater $(\mathrm{WJ} 2-\mathrm{W})$, respectively. The sequences were aligned against the

Table 1 Groundwater and geochemical parameters monitored at the depth of $20 \mathrm{~m}$ below ground surface during the deployment period

\begin{tabular}{cccccccccc}
\hline \hline Incubation time & Date & $\mathrm{DTW}^{\mathrm{a}}(\mathrm{m})$ & $\mathrm{Temp}\left({ }^{\circ} \mathrm{C}\right)$ & $\mathrm{EC}^{\mathrm{b}}(\mu \mathrm{S} / \mathrm{cm})$ & $\mathrm{Eh}(\mathrm{mV})$ & $\mathrm{pH}$ & $\mathrm{DO}(\mathrm{mg} / \mathrm{L})$ & $\mathrm{S}(-\mathrm{II})(\mu \mathrm{M})$ & $\mathrm{Fe}(\mathrm{II})(\mu \mathrm{M})$ \\
\hline$-97 \mathrm{~d}$ & 2014-Jan-2 & 5.1 & 14.4 & 224 & -159 & 6.14 & 1 & n.a. $^{\mathrm{c}}$ & n.a. \\
time 0 & 2014-Apr-9 & 4.7 & 15.5 & 207 & 165 & 6.21 & 6.89 & n.a. & n.a. \\
$33 \mathrm{~d}$ & 2014-May-12 & 4.2 & 17.3 & 223 & 78 & 6.08 & 7.24 & 0.5 & 98 \\
$69 \mathrm{~d}$ & 2014-Jun-17 & 3.9 & n.a. & n.a. & n.a. & n.a. & n.a. & n.a. & n.a. \\
$104 \mathrm{~d}$ & 2014-Jul-22 & 4.0 & 14.4 & 211 & 55 & 5.84 & 2.46 & 1.3 & 290 \\
\hline
\end{tabular}

${ }^{\mathrm{a}}$ Depth to water; ${ }^{\mathrm{b}}$ Electrical conductivity; ${ }^{\mathrm{c}}$ Not available

Table 2 A sequence summary and alpha diversity: richness and diversity indices of the samples at selected times

\begin{tabular}{|c|c|c|c|c|c|c|c|}
\hline \multirow{2}{*}{ Sample } & \multirow{2}{*}{$\begin{array}{c}\text { Subsampled } \\
\text { sequences }\end{array}$} & \multirow{2}{*}{$\begin{array}{l}\text { Good's } \\
\text { coverage }\end{array}$} & \multirow{2}{*}{$\begin{array}{l}\text { Observed } \\
\text { OTUs }\end{array}$} & \multicolumn{2}{|c|}{ Richness } & \multicolumn{2}{|c|}{ Diversity } \\
\hline & & & & Chao1 & $\mathrm{ACE}$ & Shannon & Inverse simpson \\
\hline WJ2S & 5,921 & 0.880 & 1,264 & 2,507 & 3,633 & 5.35 & 26.4 \\
\hline WJ2W & $5,921^{\mathrm{a}}$ & $0.778 \pm 0.003$ & $2,147.8 \pm 13.9$ & $4,673 \pm 142$ & $6,722 \pm 235$ & $6.85 \pm 0.01$ & $299.9 \pm 6.1$ \\
\hline
\end{tabular}

${ }^{\text {a }}$ Subsampled to 5,921 to be compared at the same number 
SILVA database ver. 102 [17], and classified using the Ribosomal Database Project 16S rRNA gene training set ver. 9, to be assigned to OTUs at a $3 \%$ dissimilarity level. For analyzing the alpha diversity of the samples, the sequence numbers were normalized to the smaller number (Table 2). Raw reads of the DNA sequencing project were deposited in NCBI's Sequence Read Archive database under the accession number PRJNA493783.

\section{Results and Discussion}

\section{Mixing of stream water and groundwater}

Annual heavy extraction of groundwater was used as an extra heat source for the greenhouses at the study site during the cold season, from early November to the April [11]. Unlike the average low levels of surface water during the dry cold season in the Korean peninsula, the stream level adjacent to the study site was raised possibly by the used groundwater runoff during heavy groundwater extraction [11], whereas heavy pumping reduced the groundwater level. It appeared that the adjacent stream water intruded the aquifer by the extraction-derived force, but there was a delay of the groundwater migration into the aquifer, probably due to properties of the porous materials with silty sediments [11]. The level of groundwater of the study borehole (WJ2) showed a gradual increase during the experiment from April to July (Table 1), which was consistent with the previously published data from a different well [11]. This helped to explain the above-described delayed response of the groundwater level from the extractionfree wells against the groundwater extraction and the stream water migration almost after the cessation of the heavy pumping in April. Thus, the migration of stream water into the groundwater was evidenced by the rise of the groundwater table during the dry season (April to May). The DO concentrations of the groundwater were quite high at the depth of $20 \mathrm{~m}$ in April and May (Table 1), suggesting the possible mixing with surface water. The relatively high concentrations of DO maintained during the migration were possibly influenced by the proximity between the borehole and the stream (approximately $30 \mathrm{~m}$ ).

In addition to DO as one of the important factors for the microbial growth, DOC is a major factor. It has been suggested that DOCs in the groundwater, which migrate along with surface water, influenced the shifts in the microbial community composition in the groundwater-surface water mixing hyporheic zone [18]. Additionally, DOCs were simulated to be migrated into the groundwater by addition to the laboratory incubations of the subsurface hyporheic zone sediments and groundwater, facilitating the shift in the microbial communities by the activities of ferric iron and sulfate reduction [19]. The shifted communities were comparable with, but different from the initial microbial composition [20]. Therefore, it was speculated that the surface water migration might have brought the DO and DOC into the groundwater and triggered microbial activities, and resulted in colonization with the
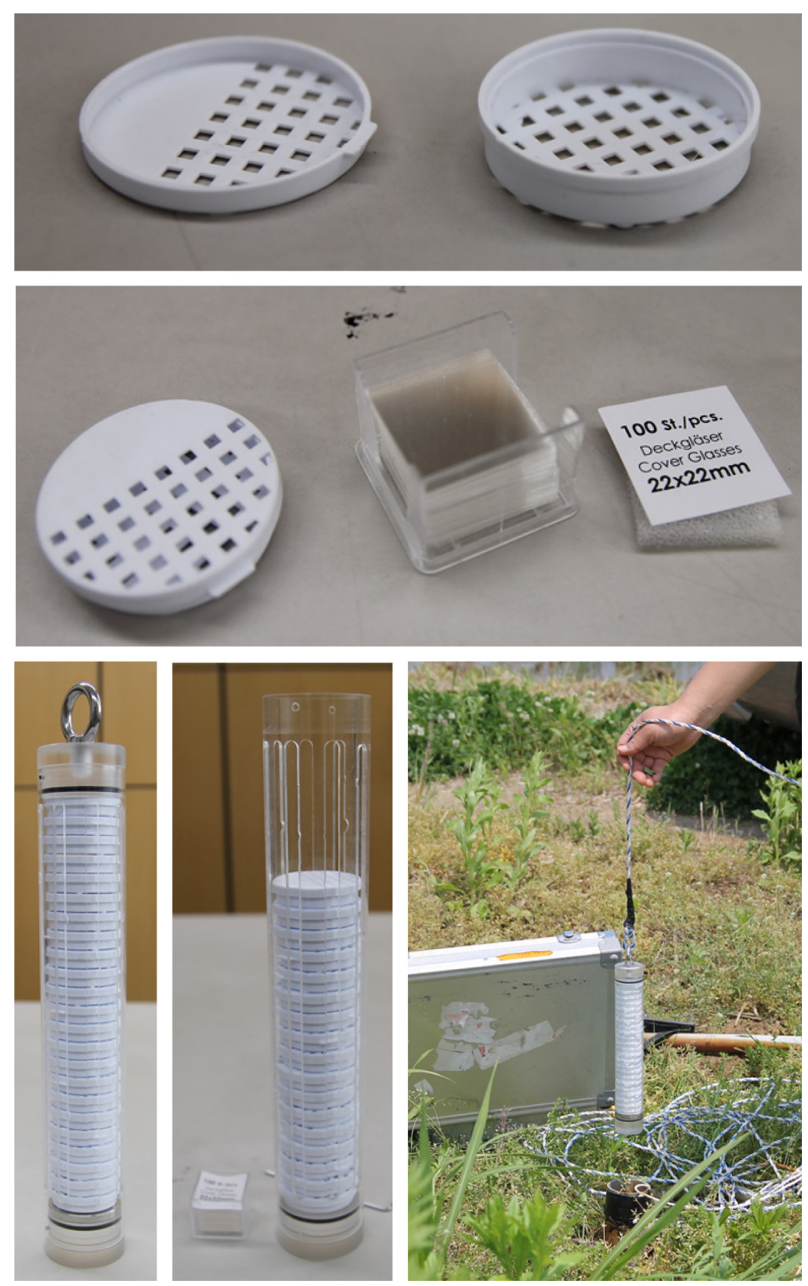

Fig. 1 Deployed units of the permeable plastic cells containing the microscopic cover glasses

shifted microbial communities.

\section{Colonization of microorganisms in the borehole}

The deployed and retrieved water-transmissible units were examined by CLSM to observe the microorganisms and EPS potentially associated with the formed sediment aggregations, using the fluorescent dyes as described above. The green and red fluorescence of the microorganisms and EPS, respectively (stained respectively by SYTO9 and lectin PHA-L), indicated that the sediment/mineral aggregates found on the retrieved glass surface after $33 \mathrm{~d}$ were associated with microbes (Fig. 2A). As the deployment duration increased, the detection of EPS and/or extracellular polysaccharides (EP) was more frequent and obvious for the samples after $69 \mathrm{~d}$ (Fig. 2B, C) and $104 \mathrm{~d}$ (Fig. 2D). In the 69-d samples, red fluorescence appeared as spots, whereas in the 104-d samples, rather broad covers of the red fluorescence were observed on the mineral aggregates. This indicated that the EPS/ EP began growth as spots and formed very slimy thin layer of biofilm in the later period as shown in Fig. 2D. Individual cells of 
(A)

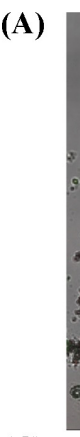

(C)
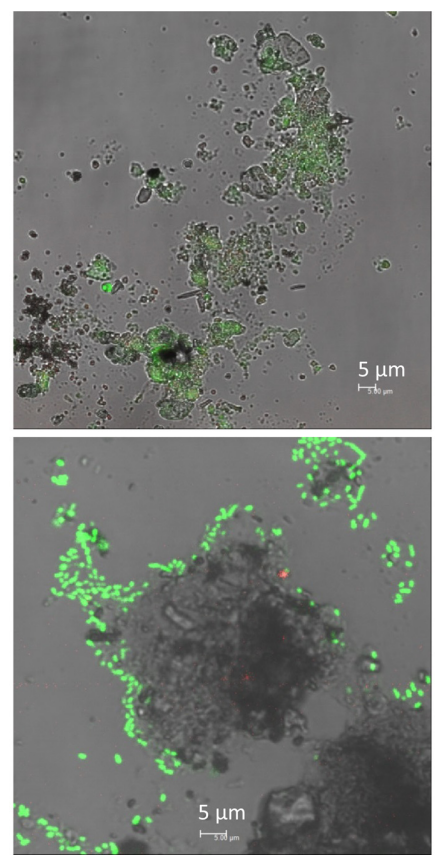

(B)

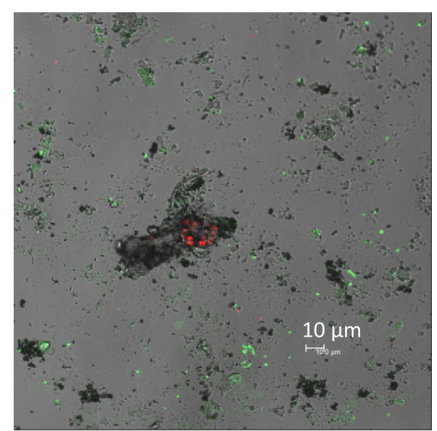

(D)

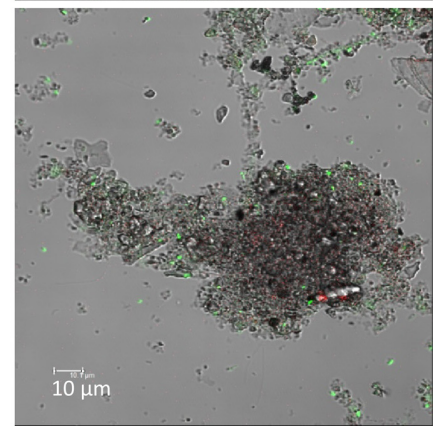

Fig. 2 CLSM images of the mineral-microbe aggregates on the retrieved glasses after $33 \mathrm{~d}(\mathrm{~A}), 69 \mathrm{~d}$ (B, C), and $104 \mathrm{~d}$ (D). Bacterial cells (nucleic acids) indicated by the green fluorescent by SYTO9 and EPS indicated by red fluorescence by lectin PHA-L

microorganisms attached to the mineral aggregates were commonly observed (Fig. 2C), which probably were members of the communities colonized on the sediments and minerals.

In order to identify the microbial community composition of the microbe-colonized mineral aggregates, both the slide glasses (WJ2S) and the groundwater (WJ2W) retrieved after $104 \mathrm{~d}$ were subjected to pyrosequencing of the amplicons of 16S rRNA gene (V1-V3 region). The subsampled sequences for normalization to be compared at the same numbers were relatively good for the community resolution, as indicated by the Good's coverages of $88 \%$ and $78 \%$ (Table 2). The number of operational taxonomic units (OTU) by 97\% similarity (species level) was larger in the groundwater-planktonic microbial community than in the glasscolonized community. This was consistent with the indices of species richness or number of different species as Chaol (estimator of total species richness) and the abundance-based estimator, with larger numbers from the groundwater community (Table 2). The diversity indices of Shannon and inverse Simpson, indicating both species richness and evenness, were also larger in the groundwater-suspended community than from the glasscolonized community (Table 2). Thus, the groundwater-suspended or planktonic microbial community (WJ2W) was larger in species numbers and those different species were relatively evenly distributed in the groundwater (WJ2W) than in the mineral aggregatesassociated community (WJ2S).

The OTUs were clustered into 20 phyla and 6 classes within the phylum Proteobacteria (Fig. 3A). Among the 20 phyla, Proteobacteria was the most abundant in both the samples (61.9 and $43.8 \%$ for $\mathrm{WJ} 2 \mathrm{~S}$ and $\mathrm{WJ} 2 \mathrm{~W}$, respectively), and Betaproteobacteria (35.0 and 19.3\%) and Deltaproteobacteria (15.3 and 6.3\%) were dominant. For the remaining portions, Bacteroidetes, Acidobacteria, and unclassified Bacteria were also abundant. The community on the glass colonization was slightly different from that in the groundwater, by the increase in Betaproteobacteria and decrease in Bacteroidetes (12.9 and 21.0\% for WJ2S and WJ2W, respectively).

When the OTUs at genus level were selected for those larger than $1 \%$ in at least one of the samples, 25 genera were included and clustered by the Bray-Curtis dissimilarity as shown by the horizontal dendrogram (Fig. 3B). There was only minor similarity between the clusters of the glass-colonized (WJ2S) and the groundwater $(\mathrm{WJ} 2 \mathrm{~W})$ communities. In the mineral-associated community (WJ2S), however, there was a relatively strongclustered group of three genera, consisting of unclassified Comamonadaceae (16.9\%), Geobacter (10.6\%), and unclassified Burkholderiales incertae sedis (5.2\%), that were not detected in the groundwater community (Fig. 3B). While the genus Geobacter is well known for ferric iron reduction, there are many ironreducing or -oxidizing bacteria both in the family Comamonadaceae and in the genera Burkholderiales incertae sedis such as Acidovorax [21], Rhodoferax [22], Albidiferax, Leptothrix, unclassified Burkholderiales bacterium [23] etc. Considering only the classified taxa down to genus level, the most abundant genus was Geobacter followed by Geothrix and Desulforhopalus (Fig. $3 \mathrm{~B}$ ), and these were iron or sulfur redox-related microorganisms. Thus, we speculated that these microorganisms such as Fe(III)reducing Geobacter and Geothrix, and sulfate-reducing Desulforhopalus might have important roles for the formation of the microbemineral associations by excreting EPS/EP. In addition, it appeared 
(A)

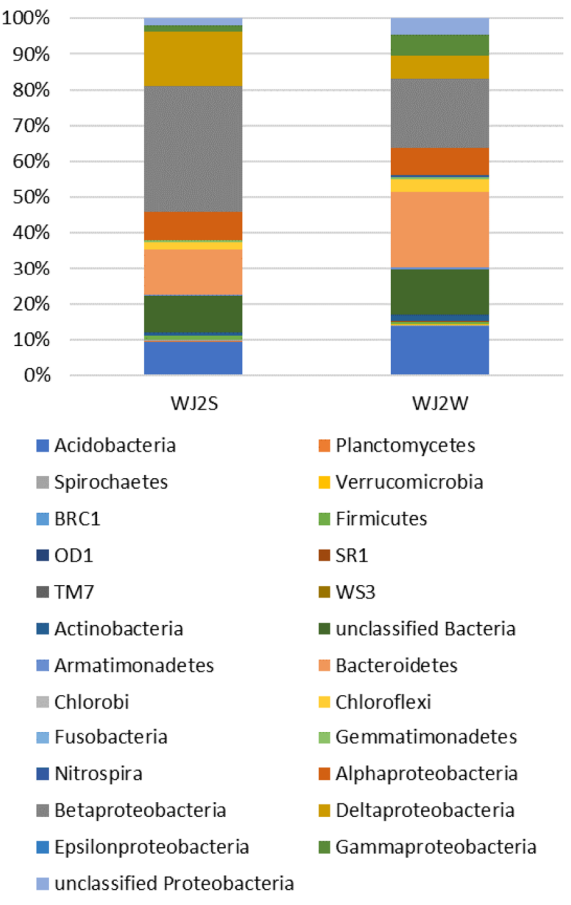

(B)
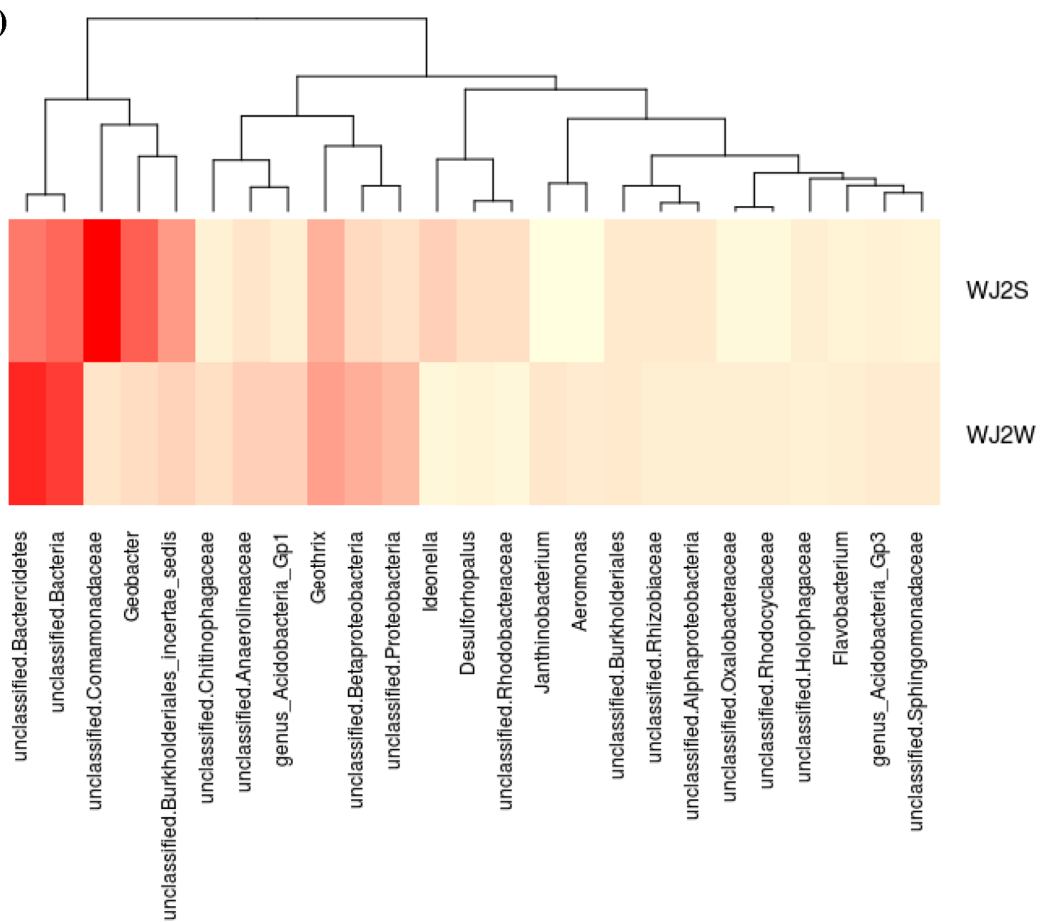

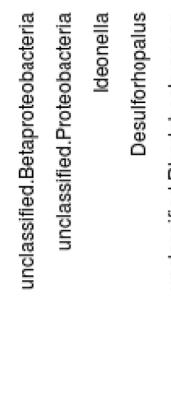

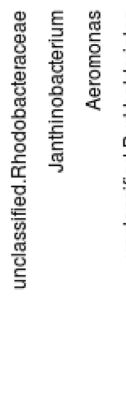

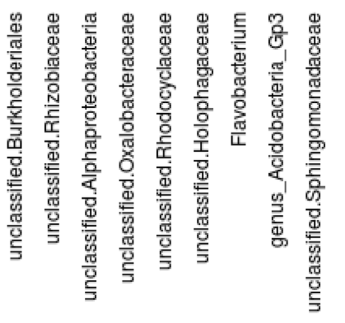

Fig. 3 Next-generation sequencing (MiSeq) of the 16S rRNA gene amplicons. (A) Relative sequence abundances at phylum level and classes within Proteobacteria. (B) A heatmap illustrating abundance of the OTUs at the genus level larger than $1 \%$ in at least one of the communities. A dendrograms on the horizontal axis is based on the Bray-Curtis dissimilarity matrix. The color gradient indicates fractions summing to 1

that the formation of those mineral-microbe associations may have grown with time, and therefore provided potentially large slimy materials to the borehole, which eventually could trigger the biofilms in the borehole and porous media as well. It was not successful to identify the formed minerals' characteristics by using X-ray diffraction and X-ray photoelectron spectroscopy, because of redox sensitive, amorphous, and small amount Fefractions with much larger fractions of sand particles. However, there were dark spotted precipitates in the mineral aggregates and those were considered as reduced phases of amorphous Fe(oxyhydr)oxides and/or ferrihydrites.

\section{Environmental implications}

In this study, microbial colonization was examined in the groundwater of the hyporheic zone, where groundwater and surface water mixing occurred. Presumably, the DO and DOC increased the microbial activities and the sediment/mineralmicrobe associations were formed. With time, the aggregates could grow as indicated by the size and EPS observations, which eventually influenced the formation of biofilms within the groundwater borehole. Moreover, the microbial community from the aggregates was featured by a cluster of iron redox-related microorganisms. We propose that these microorganisms could be the members directly producing the iron minerals within the sediment-microbe-associated aggregates. This study shows the chronological observation of the in-situ formation of sediment- microorganism-associated aggregates in the subsurface saturated porous media. The implications of this study include the potential roles of microbial compositions possibly responsible for the ironminerals formation on the biofilms within the sediment-mineralmicrobe associations.

Acknowledgments This work was supported by the Korea Institute of Geoscience and Mineral Resources (Basic Research, 14-3211) funded by the Ministry of Science, ICT and Future Planning, in part by Basic Science Research Program through the National Research Foundation of Korea funded by the Ministry of Education (2016R1D1A3B01012231), and in part by the Cooperative Research Program for Agricultural Science and Technology Development (PJ013704), Rural Development Administration, Republic of Korea.

\section{References}

1. Flemming H-C, Wingender J, Szewzyk U, Steinberg P, Rice SA, Kjelleberg S (2016) Biofilms: an emergent form of bacterial life. Nat Rev Microbiol 14: 563-575

2. Zhou B, Wang T, Li Y, Bralts V (2017) Effects of microbial community variation on bio-clogging in drip irrigation emitters using reclaimed water. Agric Water Manage 194: 139-149

3. Komlos J, Cunningham AB, Camper AK, Sharp RR (2004) Biofilm barriers to contain and degrade dissolved trichloroethylene. Environ Prog 23: 69-77

4. Pintelon TRR, Picioreanu C, van Loosdrecht MCM, Johns ML (2012) The effect of biofilm permeability on bio-clogging of porous media. Biotechnol Bioeng 109: 1031-1042 
5. Battin TJ, Besemer K, Bengtsson MM, Romani AM, Packmann AI (2016) The ecology and biogeochemistry of stream biofilms. Nat Rev Microbiol 14: 251-263

6. Kurian NK, Bhat SG (2018) Food, cosmetic and biological applications of characterized DOPA-melanin from Vibrio alginolyticus strain BTKKS3. Appl Biol Chem 61: 163-171

7. Kao CM, Chen SC, Wang JY, Chen YL, Lee SZ (2003) Remediation of PCE-contaminated aquifer by an in situ two-layer biobarrier: laboratory batch and column studies. Water Res 37: 27-38

8. Saponaro S, Negri M, Sezenna E, Bonomo L, Sorlini C (2009) Groundwater remediation by an in situ biobarrier: A bench scale feasibility test for methyl tert-butyl ether and other gasoline compounds. J Hazard Mater 167: 545-552

9. Seifert D, Engesgaard P (2012) Sand box experiments with bioclogging of porous media: Hydraulic conductivity reductions. J Contam Hydrol 136-137: 1-9

10. Nie JY, Zhu NW, Zhao K, Wu L, Hu YH (2011) Analysis of the bacterial community changes in soil for septic tank effluent treatment in response to bio-clogging. Water Sci Technol 63: 1412-1417

11. Lee J-H, Lee B-J, Unno T (2018) Bacterial communities in ground- and surface water mixing zone induced by seasonal heavy extraction of groundwater. Geomicrobiol J 35: 768-774

12. Schloss PD, Westcott SL, Ryabin T, Hall JR, Hartmann M, Hollister EB, Lesniewski RA, Oakley BB, Parks DH, Robinson CJ, Sahl JW, Stres B, Thallinger GG, Van Horn DJ, Weber CF (2009) Introducing mothur: Open-source, platform-independent, community-supported software for describing and comparing microbial communities. Appl Environ Microbiol 75: 7537-7541

13. Kim KH, Yoon Y, Hong W-Y, Kim J, Cho Y-C, Hwang S-J (2018) Application of metagenome analysis to characterize the molecular diversity and saxitoxin-producing potentials of a cyanobacterial community: a case study in the North Han River, Korea. Appl Biol Chem 61: 153161

14. Park S, Farooq A, Jo H, Kim J, Yang M, Ko Y, Kang S, Chung H, Unno
$\mathrm{T}$ (2017) Investigation of microbial communities in water dispensers. Appl Biol Chem 60: 667-672

15. Schloss PD, Gevers D, Westcott SL (2011) Reducing the effects of PCR amplification and sequencing artifacts on 16S rRNA-based studies. Plos One 6

16. Edgar RC, Haas BJ, Clemente JC, Quince C, Knight R (2011) UCHIME improves sensitivity and speed of chimera detection. Bioinformatics 27 : 2194-2200

17. Quast C et al. (2013) The SILVA ribosomal RNA gene database project: improved data processing and web-based tools. Nucleic Acids Res 41: D590-596

18. Stegen JC et al. (2016) Groundwater-surface water mixing shifts ecological assembly processes and stimulates organic carbon turnover. Nat Commun 7: 11237

19. Lee J-H et al. (2012) Microbial reductive transformation of phyllosilicate $\mathrm{Fe}(\mathrm{III})$ and U(VI) in fluvial subsurface sediments. Environ Sci Technol 46: 3721-3730

20. Lin X, Kennedy DW, Fredrickson JK, Bjornstad BN, Konopka AE (2012) Vertical stratification of subsurface microbial community composition across geological formations at the Hanford site. Environ Microbiol 14: 414-425

21. Chakraborty A, Roden EE, Schieber J, Picardal F (2011) Enhanced growth of Acidovorax sp. strain 2AN during nitrate-dependent $\mathrm{Fe}$ (II) oxidation in batch and continuous-flow systems. Appl Environ Microbiol 77: 8548-8556

22. Finneran KT, Johnsen CV, Lovley DR (2003) Rhodoferax ferrireducens sp. nov., a psychrotolerant, facultatively anaerobic bacterium that oxidizes acetate with the reduction of Fe(III). Int J Syst Evol Microbiol 53: 669-673

23. Fukushima J, Tojo F, Asano R, Kobayashi Y, Shimura Y, Okano K, Miyata N (2015) Complete genome sequence of the unclassified ironoxidizing, chemolithoautotrophic Burkholderiales bacterium GJ-E10, isolated from an acidic river. Genome Announc 3: e01455-01414 